\title{
Water and sodium intake habits and status of ultra-endurance runners during a multi-stage ultra-marathon conducted in a hot ambient environment: an observational field based study
}

\author{
Ricardo JS Costa ${ }^{1,2^{*}}$, Ana Teixeira ${ }^{3}$, Luis Rama ${ }^{3}$, Abigail JM Swancott², Lisa D Hardy², Benjamin Lee², \\ Vera Camões-Costa ${ }^{4}$, Samantha Gill ${ }^{2}$, Jessica P Waterman², Emily C Freeth ${ }^{1}$, Edel Barrett ${ }^{1}$, Joanne Hankey ${ }^{2}$, \\ Slawomir Marczak ${ }^{2}$, Encarna Valero-Burgos ${ }^{5}$, Volker Scheer ${ }^{6}$, Andrew Murray ${ }^{7}$ and Charles D Thake ${ }^{2}$
}

\begin{abstract}
Background: Anecdotal evidence suggests ultra-runners may not be consuming sufficient water through foods and fluids to maintenance euhydration, and present sub-optimal sodium intakes, throughout multi-stage ultra-marathon (MSUM) competitions in the heat. Subsequently, the aims were primarily to assess water and sodium intake habits of recreational ultra-runners during a five stage $225 \mathrm{~km}$ semi self-sufficient MSUM conducted in a hot ambient environment ( $T_{\max }$ range: $32^{\circ} \mathrm{C}$ to $40^{\circ} \mathrm{C}$ ); simultaneously to monitor serum sodium concentration, and hydration status using multiple hydration assessment techniques.
\end{abstract}

Methods: Total daily, pre-stage, during running, and post-stage water and sodium ingestion of ultra-endurance runners (UER, $n=74)$ and control (CON, $n=12)$ through foods and fluids were recorded on Stages 1 to 4 by trained dietetic researchers using dietary recall interview technique, and analysed through dietary analysis software. Body mass (BM), hydration status, and serum sodium concentration were determined pre- and post-Stages 1 to 5 .

Results: Water (overall mean (SD): total daily 7.7 (1.5) L/day, during running $732(183) \mathrm{ml} / \mathrm{h}$ ) and sodium (total daily 3.9

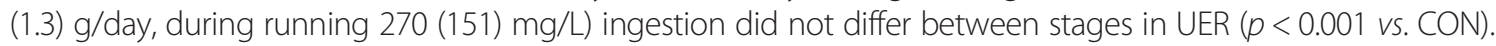
Exercise-induced BM loss was $2.4(1.2) \%(p<0.001)$. Pre- to post-stage BM gains were observed in $26 \%$ of UER along competition. Pre- and post-stage plasma osmolality remained within normal clinical reference range (280 to 303 $\mathrm{mOsmol} / \mathrm{kg}$ ) in the majority of UER ( $p>0.05$ vs. CON pre-stage). Asymptomatic hyponatraemia $(<135 \mathrm{mmol} / \mathrm{L})$ was evident pre- and post-stage in $n=8$ UER, corresponding to $42 \%$ of sampled participants. Pre- and post-stage urine colour, urine osmolality and urine/plasma osmolality ratio increased $(p<0.001)$ as competition progressed in UER, with no change in CON. Plasma volume and extra-cellular water increased $(p<0.001) 22.8 \%$ and $9.2 \%$, respectively, from pre-Stage 1 to 5 in UER, with no change in CON.

Conclusion: Water intake habits of ultra-runners during MSUM conducted in hot ambient conditions appear to be sufficient to maintain baseline euhydration levels. However, fluid over-consumption behaviours were evident along competition, irrespective of running speed and gender. Normonatraemia was observed in the majority of ultra-runners throughout MSUM, despite sodium ingestion under benchmark recommendations.

Keywords: Water, Drinking, Beverages, Total body water, Dehydration, Euhydration, Hyponatraemia, Carbohydrate

\footnotetext{
* Correspondence: ricardo.costa@coventry.ac.uk

'Department of Health Professions, Coventry University, Priory Street,

Coventry CV1 5FB, United Kingdom

${ }^{2}$ Sport \& Exercise Science Applied Research Group, Coventry University, Priory

Street, Coventry CV1 5FB, United Kingdom

Full list of author information is available at the end of the article
} 


\section{Introduction}

Multi-stage ultra-marathon (MSUM) events, commonly conducted in hot ambient conditions $\left(\geq 30^{\circ} \mathrm{C}\right)$ and routed over undulating desert based terrains, expose ultra-runners to exercise-heat stresses with minimal external support. Due to the well established association between compromised hydration status and decrement in endurance exercise performance [1], programming of individualised hydration strategies before and during MSUM aimed at maintaining euhydration during exercise-heat stress is of prime importance [2]. Maintaining euhydration during consecutive days of endurance running in hot ambient conditions is reported to attenuate cardiovascular and thermoregulatory strain, assists heat acclimatisation, and mitigates clinically significant conditions (e.g. exertional heat illnesses) from occurring [3-5].

During MSUM, besides the exposure to exercise-heat stress on consecutive days (normally ranging from 5 to 8 days), ultra-runners need to consume sufficient water (through foods and fluids) to maintain euhydration throughout competition. In some cases (e.g. selfsufficient MSUM) ultra-runners must ration water supplies (e.g. $\sim 12 \mathrm{~L} /$ day provisions), enforcing a potential barrier to maintaining euhydration. Indeed, anecdotal evidence suggests ultra-runners may not be consuming sufficient water through foods and fluids to support consistent maintenance of euhydration along MSUM competition (2009 Al Andalus Ultimate Trail, Loja, Spain). This may possibly due to the lack of nutritional education, ultra-endurance sports cultural trends, time limitations and motivation for appropriate food-fluid preparation and consumption [6,7]. Additionally, practical reallife factors (e.g. dysfunction to thirst and palate sensations, suppressed appetite, competition anxiety, gastrointestinal distress, and/or fluid disinterest) may also limit total water ingestion during consecutive days of exercise-heat stress [6-12]. However, a comprehensive assessment of water ingestion and hydration status of ultra-runners during MSUM conducted in a hot ambient environment has not previously been conducted to confirm these possibilities.

Fluid intake recommendations for endurance exercise have previously been proposed [1,13-15]. For consecutive days of endurance exercise in the heat, it is recommended to initiate exercise in a euhydrated state, and consume sufficient fluids (potentially using thirst as an indicator for fluid consumption) during exercise to prevent substantial depletions in body water [1,13-15]. BM losses $\geq 2 \%$ have previously been linked to changes in haemorheology, metabolic dysregulation, heat intolerance, cardiovascular strain, and subsequent inability to maintain exercise workload $[1,5,13]$. Interestingly, $\mathrm{BM}$ losses $\geq 2 \%$ are a common feature amongst highly trained endurance runners during competition [16,17]. It is suggesting that BM loss, to a certain extent, during running does not substantial impact on the maintenance of exercise workload in faster runners $[16,17]$.

Adequate dietary sodium and/or the inclusion of sodium in fluids (700 to $1200 \mathrm{mg} / \mathrm{L}$ ) during exercise and recovery has previously been recommended to stimulate thirst, increase voluntary fluid intake, enhance glucose and water intestinal absorption, optimise extracellular and intracellular fluid balance, and potentially mitigate clinical significant episodes of hyponatraemia from occurring [18-21]. The inclusion of sodium within ingested fluids and/or sodium supplementation during exercise is a common practice amongst endurance athletes, and a persistent belief of essential requirement amongst the ultra-endurance population. It has however recently been proposed that sodium supplementation in fluids is not required during endurance exercise in the heat, since sodium losses (e.g. sweat, urine, and faeces) appear to be attenuated during periods of sodium restriction or deprivation [14,22,23]. However, a comprehensive assessment of sodium ingestion and status of ultra-runners during MSUM conducted in a hot ambient environment has not previously been conducted to confirm appropriate sodium ingestion advice to this population.

Due to the exceptional fear of dehydration commonly surrounding the ultra-endurance population, current hydration advice given to ultra-runners at the competition location is largely focused on consuming 'as much fluid as tolerated' (plus inclusion of sodium supplementation), with further advice advocating increased drinking frequency to produce a consistent clear urine output along competition. This behaviour potentially poses a threat in promoting clinical manifestations of hyponatraemia in high risk groups, especially runners that may suffer from the syndrome of inappropriate anti-diuretic hormone secretion [24-26]. Moreover, it has previously been acknowledged that runners who complete the designated course using a mixture of walking and running (mean speed $\leq 8 \mathrm{~km} / \mathrm{h}$ ) demonstrated more fluid over-consumption behaviours than those who predominantly run the entire designated course (mean speed $\geq 8 \mathrm{~km} / \mathrm{h}$ ) $[17,24,26]$, suggesting higher hyponatraemic risk in slower runners. Interestingly, MSUM is a type of event that nurtures the development of such drinking behaviours in thermoneutral conditions [27], but to date, no study has determined hyponatraemia inducing drinking behaviours or incidence along MSUM competition conducted in hot ambient conditions.

Various methods of determining hydration status have previously been proposed and reviewed, with limitations and strengths being observed in all methods $[28,29]$. To avoid misinterpretation of hydration status, the use of multiple techniques (e.g. pre- to post-exercise BM change, plasma $\left(\mathrm{P}_{\text {Osmol }}\right)$ and urine $\left(\mathrm{U}_{\text {Osmol }}\right)$ osmolality, multi-frequency bioelectrical impedance analysis) when assessing hydration status of athletic populations is 
suggested $[28,29]$. With this in mind, the aims of the current observational field study were primarily to assess water and sodium intake habits of recreational ultrarunners during a semi self-sufficient MSUM conducted in a hot ambient environment; simultaneously monitor serum sodium concentration and hydration status using multiple hydration assessment techniques, along competition. It was hypothesised that firstly, water intake habits of ultra-runners will not be sufficient to consistently maintain baseline euhydration levels throughout competition; secondly sodium intake will be sufficient to maintain normonatraemia along the MSUM.

\section{Methods}

\section{Setting}

The study was conducted during the 2010 and $2011 \mathrm{Al}$ Andalus Ultimate Trail (www.alandalus-ut.com), held during the second week of July, in the region of Loja, Spain. The MSUM was conducted over five stages (five days) totalling a distance of $225 \mathrm{~km}$ (Table 1), which was performed on a variety of terrains; predominantly offroad trails and paths, but also included steep and narrow mountain passes, and occasional road. Average running intensity for the MSUM was 7.2 (0.9) METs (SenseWear 7.0, BodyMedia Inc., Pittsburgh, PA, USA). Sleeping arrangements from Stages 1 to 5 included a combination of outdoor tent and village sports hall accommodation.

\section{Participants}

After ethical approval from the Coventry University Ethics Committee that conforms with the 2008 Helsinki declaration for human research ethics, a convenience sampling observational cohort was studied, whereby 74 out of 134 ultra-runners entered into the MSUM competition, from various continents around the world (e.g. Europe, Africa, Asia, Australasia, North and South Americas), volunteered to participate in the study [mean: UER (Males $n=46$, Females $n=28$ ): age 41 (8) years, height 169 (14) cm, BM 70 (11) kg, body fat mass 17 (5)\%]. Additionally, 12 age and anthropometrically matched individuals who accompanied the UER along the MSUM course as support crews, but did not compete (absence of exercise stress), volunteered to participate in the study as part of the control group [CON (Males $n=5$, Females $n=7$ ): age 35 (13) years, height 167 (9) cm, BM 70 (16) kg, body fat mass 21 (6)\%], for comparative purposes only. Additionally, for the purpose of data analysis, participants were divided into two groups. A slow group (SR; final ranking range: 46 to 108), who completed the entire distance of the MSUM using a mixture of walking and running (overall mean speed $<8 \mathrm{~km} / \mathrm{h}$ ); and a fast group (FR; final ranking range: 2 to 44), who completed the majority of the MSUM distance running (overall mean speed $\geq 8 \mathrm{~km} / \mathrm{h}$ ). This criterion was predetermined, and participants were

Table 1 Stage time and average speed of UER along MSUM competition

\begin{tabular}{|c|c|c|c|}
\hline & UER & SR & FR \\
\hline Stage description & $\begin{array}{l}\text { Running time (h:min) } \\
\text { and speed (km/h) }\end{array}$ & $\begin{array}{l}\text { Running time (h:min) } \\
\text { and speed (km/h) }\end{array}$ & $\begin{array}{c}\text { Running time (h:min) } \\
\text { and speed (km/h) }\end{array}$ \\
\hline Stage 1: $37 \mathrm{~km}$ & 4:54 (0:51) & $5: 29(0: 35)$ & $4: 10(0: 28)$ \\
\hline 503 to $1443 \mathrm{~m} \mathrm{ASL}$ & $7.6(1.4)$ & $6.8(0.7)$ & $8.9(1.0)$ \\
\hline \multicolumn{4}{|l|}{$T_{\max }: 32^{\circ} \mathrm{C} ; \mathrm{RH}_{\max }: 32 \%$} \\
\hline Stage 2: $45 \mathrm{~km}$ & $6: 37(1: 20)$ & $7: 32(1: 06)$ & $5: 38(0: 46)$ \\
\hline 830 to $1338 \mathrm{~m} \mathrm{ASL}$ & $6.8(1.3)$ & $6.0(0.8)$ & $8.0(1.0)$ \\
\hline \multicolumn{4}{|l|}{$T_{\max }: 34^{\circ} \mathrm{C} ; \mathrm{RH}_{\max }: 33 \%$} \\
\hline Stage 3: $40 \mathrm{~km}$ & $4: 59(0: 53)$ & $5: 37(0: 39)$ & $4: 15(0: 27)$ \\
\hline 689 to $1302 \mathrm{~m} \mathrm{ASL}$ & $8.0(1.6)$ & $7.1(0.9)$ & $9.4(1.2)$ \\
\hline \multicolumn{4}{|l|}{$T_{\max }: 38^{\circ} \mathrm{C} ; R_{\max }: 37 \%$} \\
\hline Stage 4: 65 km & $7: 51(1: 25)$ & $8: 52(1: 01)$ & $6: 48(0: 54)$ \\
\hline 671 to $1152 \mathrm{~m} \mathrm{ASL}$ & $8.3(1.8)$ & $7.3(1.0)$ & $9.6(1.7)$ \\
\hline \multicolumn{4}{|l|}{$T_{\max }: 40^{\circ} \mathrm{C} ; \mathrm{RH}_{\max }: 33 \%$} \\
\hline Stage 5: 38 km & $4: 16(1: 05)$ & 4:49 (1:05) & $3: 35(0: 35)$ \\
\hline 473 to $1065 \mathrm{~m} \mathrm{ASL}$ & $8.9(2.1)$ & $7.9(1.6)$ & $10.6(1.7)$ \\
\hline \multicolumn{4}{|l|}{$T_{\max }: 40^{\circ} \mathrm{C} ; R H_{\max }: 40 \%$} \\
\hline \multirow[t]{2}{*}{ Total: 225 km } & 28:03 (4:34) & $31: 52(2: 51)$ & $24: 22(2: 20)$ \\
\hline & $8.0(1.4)$ & $7.1(0.6)$ & $9.2(0.9)$ \\
\hline
\end{tabular}

Mean (SD): UER ( $n=74$ ); slow runners (SR: MSUM mean speed $<8 \mathrm{~km} / \mathrm{h}, n=41$ ); fast runners (FR: MSUM mean speed $\geq 8 \mathrm{~km} / \mathrm{h}, n=33$ ). 
grouped according to their overall race time, prior to data analysis. All participants arrived at the MSUM location $\leq 48 \mathrm{~h}$ prior to the start of Stage 1. Only $28 \%$ of participants resided in countries with hot ambient conditions similar to those of the race location $\left(\geq 30^{\circ} \mathrm{C}\right)$ at the time of competition; whilst the remaining $72 \%$ of participants resided in countries that presented cold or thermoneutral environmental conditions $\left(\leq 20^{\circ} \mathrm{C}\right)$.

\section{Study design and data collection}

Following participant recruitment and informed consent, preliminary measures were taken to determine participant characteristics. Height was measured by a wall-mounted stadiometer. Baseline BM was determined using calibrated electronic scales (BF510, Omron Healthcare, Ukyo-ku, Kyoto, Japan) placed on a hard levelled surface. Waist and hip circumferences were measured using a standard clinical tape measure by trained researchers. BM and circumference measures were used in conducting multi-frequency bioelectrical impedance analysis (Quadscan 4000, Bodystat, Douglas, Isle of Man, UK), which was used to determine body composition.

The current MSUM was semi self-sufficient, whereby participants (including CON) planned and provided their own foods and fluids (except plain water) along the five days of competition. Participants' equipment and sustenance was transported to each stage section by the race organisation. Only plain water was provided by the race organisers ad libitum during the rest phase throughout competition. Additionally, aid stations along the running phase of competition were situated approximately $10 \mathrm{~km}$ apart, and only provided plain water, fruit (oranges and watermelon), and electrolyte supplementation (Elete electrolyte add-in, Mineral Resources International, South Ogden, Utah, US). Participants were advised to adhere to their programmed habitual dietary practices throughout the entire MSUM competition.

Each day, for five consecutive days, running stages commenced at either 08:00 or 09:00 h. All participants consumed their breakfast 2 to $3 \mathrm{~h}$ before the start of each stage. Within the hour before the start of each running stage, pre-stage measurements were determined and samples collected. Participants were required to provide a mid-flow urine sample ( $2^{\text {nd }}$ urine of the day upon waking) into $30 \mathrm{ml}$ universal tubes (HR 120-EC, A \& D instruments, Tokyo, Japan), prior to BM measurements. Participants were then required to sit for 10 minutes before whole blood sampling, which was collected by venepuncture without venostasis from an antecubital vein using a $21 \mathrm{G}$ butterfly syringe into one lithium heparin vacutainer tube $(6 \mathrm{ml}, 1.5 \mathrm{IU} / \mathrm{ml}$ heparin; Becton Dickinson, Oxford, UK), one $\mathrm{K}_{3}$ EDTA vacutainer tube $(6 \mathrm{ml}$, $1.6 \mathrm{mg} / \mathrm{ml}$ of ethylenediaminetetraacetic acid; Becton Dickinson, Oxford, UK), and one plain vacutainer tube
(4 ml, Becton Dickinson, Oxford, UK). Blood samples were immediately (or after clotting in plain vacutainer samples) centrifuged at $1500 \mathrm{~g}$ for 10 minutes at $4^{\circ} \mathrm{C}$ (Heraeus Labofuge 400R, Kendro Laboratory, Langenselbold, Germany); plasma and serum were aliquoted into eppendorfs and stored frozen initially at $-20^{\circ} \mathrm{C}$ during the MSUM competition, prior to transferring to $-80^{\circ} \mathrm{C}$ storage after completion of the experimental procedure. Participants were then required to lay supine for 10 minutes before conducting multi-frequency bioelectrical impedance analysis. During this time, the conduction body points (right hand and foot) were cleaned and air-dried prior to electrode attachment and analysis. BM was re-measured in those participants who needed to urinate before the stage start. Immediately post-stage and before any foods or fluids were ingested, BM was measured, followed by blood sampling, as previously described. Participants were then asked to provide a midflow urine sample at their earliest convenience. For consistency, the order and methods of pre- and post-stage measurements and sampling were identical and standardised for all stages.

At the end of each competition day (20:00 to 22:00 h) on Stages 1 to 4 , trained dietetic researchers $(n=8)$ conducted a standardised structured interview (dietary recall interview technique) on participants (UER and CON) to ascertain total daily food and fluid ingestion. Due to practical and participant factors, it was not feasible to conduct the daily dietary assessment on Stage 5, since MSUM completion occurred within the duration of Stage 5 , not completing a $24 \mathrm{~h}$ period. To avoid interobserver variations, each trained researcher conducted the interview on the same UER throughout the entire MSUM. Participants were educated and instructed to recall in detail all foods and fluids ingested along the competition day, which included specified food and beverage quantities (e.g. g, ml, litres, portions) and qualities (e.g. type of foods-beverages, brands of foods-beverages) ingested for breakfast (pre-stage), during the stage (during running), within the hour after stage completion (post-stage), and from the hour post-stage until sleep. Any foods and fluids that were part of a meal, snack, or beverage that were not ingested (food wastage) were recorded and not included within the dietary analysis procedure. Relevant nutritional information from all food-beverage packages was recorded. The addition of carbohydrate, protein, sodium (including salt), and/or mixed macronutrient supplementations to foods and fluids were also recorded, and used in the dietary analysis.

\section{Dietary analysis}

Total daily water and sodium intakes, water and sodium intakes pre-stage, during running, and post-stage through foods and fluids were calculated through Dietplan6 dietary analysis software (v6.60, Forestfield Software, Horsham, 
West Sussex, UK) by a trained dietetic researcher. To improve the validity of the dietary analysis, all the nutritional information gathered from food-beverage packages during the interview procedure was entered into the dietary analysis software program. In addition, to improve the reliability of the dietary analysis, all the completed dietary interview logs were blindly analysed by a $2^{\text {nd }}$ trained dietetic researcher. The overall mean inter-observer coefficiency of variation for fluid and sodium variables analysed was $0.7 \%$ and $5.2 \%$, respectively.

\section{Assessment of hydration status}

Exercise-induced BM change (pre- to post-stage BM difference) was determined from pre- and post-stage BM values. $\mathrm{U}_{\text {Osmol }}$ was determined from $300 \mu \mathrm{l}$ of pre- and post-stage urine samples (Osmocheck, Vitech Scientific, Partridge Green, West Sussex, UK), while the remainder of the urine sample was used to determine urine colour $\left(\mathrm{U}_{\text {Colour }}\right)$ as previously reported [30]. Pre- and post-stage $\mathrm{P}_{\text {Osmol }}$ was determined from $50 \mu \mathrm{l}$ lithium heparin plasma samples in duplicate by freezepoint osmometry (Osmomat 030, Gonotec, Germany), as previously recommended [31]. Additionally, $\mathrm{U}_{\text {Osmol }} / \mathrm{P}_{\text {Osmol }}$ ratio was calculated to identify discrepancies between $\mathrm{U}_{\mathrm{Osmol}}$ and $\mathrm{P}_{\mathrm{Osmol}}$ along the experimental design [32]. Plasma volume $\left(\mathrm{P}_{\mathrm{V}}\right)$ changes were estimated from the haemoglobin and haematocrit content of $\mathrm{K}_{3} \mathrm{EDTA}$ whole blood samples (Coulter Ac $\mathrm{T}$ diff, Beckman Coulter Inc., Indianapolis, USA) $[33,34]$, as previously reported [16,35-37]. Pre- and poststage serum sodium $\left(\mathrm{S}_{\mathrm{Na}}\right)$ concentration was determined by ion selective electrode analysis (SpotLyte, Menarini Pharmaceuticals, Florance, Italy). Multi-frequency bioelectrical impedance analysis was used to determine pre-stage total body, extra-cellular, and intra-cellular water. In CON, hydration was assessed pre-Stages 1, 3 and 5 only.

\section{Data analysis}

Data in the text (overall mean value otherwise specified), tables, and figures are presented as mean value and standard deviation (SD). Participants presenting incomplete data sets were removed prior to data analysis ( $n$ presented in tables and figures for each variable). Fluid intake variables were analysed and are reported as water ingestion through foods and fluids throughout the results section. Considering the potential influence of individual BM differences (especially in relation to gender and training status) on fluid intake variables, data analysis was performed on total values and corrected for BM, as previously reported [38]. Whereas, data analysis for sodium variables were performed for total values and concentration per fluid volume ingested. Descriptive statistics were used to explore quality of fluids ingested. A one-way ANOVA was applied to determine differences in variables between stages, while a two-way ANOVA was applied to determine differences between groups (UER vs. CON; SR $v s$. FR; male vs. female ultra-runners), and between preand post-stage values within stages (SPSS v.17.0.2, Illinois, US). Assumptions of homogeneity were checked, with adjustments to the degrees of freedom and verification by non-parametric equivalents (Kruskal-Wallis and Friedman two-way, respectively) where appropriate. Significant main effects were analysed using post hoc Tukey's HSD test. The acceptance level of significance was set at $p<$ 0.05 .

\section{Results}

\section{Fluid intake}

Total daily water ingestion was higher on Stage 4 compared with Stage 3 only in UER $(p=0.007)$ and SR $(p=0.034)$; but did not vary between stages in CON and FR (Table 2). Similarly, when corrected for BM, total daily water ingestion was higher on Stage 4 compared with Stage 3 in UER $(p=0.034)$, and Stages 2 and 3 in SR $(p=0.05)$; but did not vary between stages in $\mathrm{CON}$ and FR. Daily water ingestion (total and corrected for $\mathrm{BM}$ ) was consistently higher in UER compared with CON throughout the MSUM $(p<0.001)$. While, total daily water ingestion was higher $(p=0.002)$ in FR compared with SR on Stage 2 only; but when corrected for BM, no differences were observed. Plain water accounted for $73 \%$ (SR 74\%, FR 72\%) and 41\% of total daily fluids consumed by UER and CON, respectively; with remaining fluid ingestion coming from nutrient rich sources, which included (in order of highest consumed volume in UER): soft drinks, fruit juices, carbohydrate solutions, carbohydrateprotein solutions, milks, and protein solutions.

Pre-stage water ingestion (total and corrected for $\mathrm{BM})$ was lower on Stages 3 and 4 for UER, and stages 2 and 3 for SR, compared with Stage $1(p<0.05)$; but did not vary between stages in FR (Table 3). Pre-stage water ingestion (total and corrected for BM) did not differ between SR and FR within stages. Plain water accounted for $75 \%$ (SR 78\%, FR 71\%) of total fluids consumed pre-stage by UER, with remaining fluid ingestion coming from nutrient rich sources, which included (in order of highest consumed volume in UER): fruit juices, milks, carbohydrate solutions, and carbohydrateprotein solutions.

Total water ingestion during running was lower on Stages 1,2 , and 3 in UER $(p<0.001)$ and SR $(p<0.001)$, and lower on Stages 1 and 3 in FR $(p=0.005)$, compared with Stage 4 (Figure 1A). Similar results were observed when corrected for BM (Figure 1B). No difference in water ingested (total and corrected for BM) during running was observed between SR and FR within all stages. Even though the rate of water ingestion during running did not differ between stages in UER, FR presented a higher water ingestion rate compared with SR in Stages 
Table 2 Total daily water ingestion of UER along MSUM competition

\begin{tabular}{|c|c|c|c|c|c|}
\hline & Stage 1 & Stage 2 & Stage 3 & Stage 4 & Overall mean \\
\hline \multicolumn{6}{|c|}{ Total daily water intake (ml/day) } \\
\hline UER & $7560(1540)^{\mathrm{bb}}$ & $7488(2041)^{\mathrm{bb}}$ & $7075(1842)^{\ddagger \neq b b}$ & $8313(2282)^{\mathrm{bb}}$ & $7709(1499)^{\mathrm{bb}}$ \\
\hline $\mathrm{CON}$ & $2806(290)$ & $3411(201)$ & $3277(601)$ & $3710(670)$ & $3301(163)$ \\
\hline SR & 7575 (1608) & $6986(2221)^{c}$ & $6729(2025)^{\ddagger}$ & $8193(2581)$ & $7371(1648)$ \\
\hline FR & $8520(1272)$ & $8218(1510)$ & $7578(1436)$ & $8487(1806)$ & $8201(1110)$ \\
\hline \multicolumn{6}{|c|}{ Total daily water intake corrected for BM } \\
\hline \multicolumn{6}{|c|}{ (ml/kgBM/day) } \\
\hline UER & $116(24)^{\mathrm{bb}}$ & $111(33)^{\mathrm{bb}}$ & $106(31)^{\neq b b}$ & $124(39)^{\mathrm{bb}}$ & $114(26)^{\mathrm{bb}}$ \\
\hline $\mathrm{CON}$ & $50(18)$ & $60(14)$ & $53(7)$ & $59(14)$ & $56(6)$ \\
\hline SR & $113(27)$ & $106(34)^{\ddagger \neq}$ & $103(35)^{\ddagger \neq}$ & $125(43)$ & $112(29)$ \\
\hline FR & $119(18)$ & $119(29)$ & $111(25)$ & $123(36)$ & $118(22)$ \\
\hline
\end{tabular}

Mean (SD): UER ( $n=54$ ); control (CON, $n=12$ ); slow runners (SR; MSUM mean speed $<8 \mathrm{~km} / \mathrm{h}, n=32$ ); fast runners (FR; MSUM mean speed $\geq 8 \mathrm{~km} / \mathrm{h}, n=22$ ).

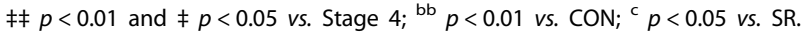

1 to $3(p<0.001$; Figure $1 C)$. Plain water accounted for $79 \%$ of total fluids consumed during running by UER (SR: 78\%, FR: 80\%); with remaining fluid ingestion coming from nutrient rich sources, which included (in order of highest consumed volume in UER): carbohydrate solutions, soft drinks, carbohydrate-protein solutions, and fruit juices. Additionally, 26\% of UER reported consuming only plain water during running throughout the entire MSUM.

No difference was observed for post-stage water ingestion (total and corrected for BM) between stages for UER, SR and FR (Table 3). Whereas, total post-stage water ingestion was higher $(p<0.001)$ in FR compared with SR on Stages 1 and 3. However, when corrected for $\mathrm{BM}$, no difference was observed between SR and FR within stages. Plain water accounted for 45\% (SR 45\%, FR $46 \%$ ) of total fluids consumed post-stage by UER, with remaining fluid ingestion coming from nutrient rich sources, which included (in order of highest consumed volume in UER): soft drinks, fruit juices, carbohydrate solutions, carbohydrate-protein solutions, protein solutions, and milks.

When comparing male and female ultra-runners, no significant difference in total daily (male 7884 (1652) $\mathrm{ml} /$

Table 3 Total pre-stage and immediately post-stage total water ingestion of UER along MSUM competition

\begin{tabular}{|c|c|c|c|c|c|}
\hline & Stage 1 & Stage 2 & Stage 3 & Stage 4 & Overall mean \\
\hline \multicolumn{6}{|c|}{ Pre-stage (ml) } \\
\hline UER & $1052(640)$ & $831(511)$ & $767(436)^{\dagger}$ & $767(398)^{+}$ & 854 (385) \\
\hline$S R$ & $1112(967)$ & $782(521)^{\dagger}$ & $784(432)^{\dagger}$ & $803(401)$ & $870(387)$ \\
\hline$F R$ & $967(530)$ & $902(500)$ & $742(452)$ & 715 (398) & $831(390)$ \\
\hline \multicolumn{6}{|c|}{ Pre-stage (ml/kgBM) } \\
\hline UER & $15.2(9.1)$ & $12.2(7.3)$ & $11.4(7.3)^{\dagger}$ & $11.3(5.8)^{\dagger}$ & $12.5(5.3)$ \\
\hline$S R$ & $16.2(9.8)$ & $11.5(6.7)^{\dagger}$ & $11.7(5.7)^{\dagger}$ & $12.0(5.4)$ & $12.8(5.0)$ \\
\hline$F R$ & $13.7(7.8)$ & $13.1(8.1)$ & $11.1(7.6)$ & $10.3(6.4)$ & $12.0(6.3)$ \\
\hline \multicolumn{6}{|c|}{ Post-stage (ml) } \\
\hline UER & $1396(716)$ & $1171(667)$ & $1179(621)$ & $1116(607)$ & $1214(504)$ \\
\hline$S R$ & $1201(696)$ & $1053(536)$ & $1014(464)$ & $1004(594)$ & $1068(385)$ \\
\hline$F R$ & $1604(667)^{c}$ & $1342(804)$ & $1418(744)^{c}$ & $1280(602)$ & $1426(587)^{c c}$ \\
\hline \multicolumn{6}{|c|}{ Post-stage (ml/kgBM) } \\
\hline UER & $20.8(11.2)$ & $17.7(10.3)$ & $17.7(9.4)$ & $16.9(9.9)$ & $18.3(7.9)$ \\
\hline$S R$ & $18.7(11.8)$ & $16.4(8.9)$ & $15.8(8.1)$ & $15.8(10.4)$ & $16.6(7.1)$ \\
\hline $\mathrm{FR}$ & $24.0(9.6)$ & $19.6(12.0)$ & $20.5(10.7)$ & $18.6(9.0)$ & 20.7 (8.6) \\
\hline
\end{tabular}

Mean (SD): UER ( $n=54$ ); slow runners (SR; MSUM mean speed $<8 \mathrm{~km} / \mathrm{h}, n=32$ ); fast runners (FR; MSUM mean speed $\geq 8 \mathrm{~km} / \mathrm{h}, n=22$ ). $+p<0.05 \mathrm{vs}$. Stage 1 ; ${ }^{c c} p<0.01$ and ${ }^{c} p<0.05$ vs. SR. 

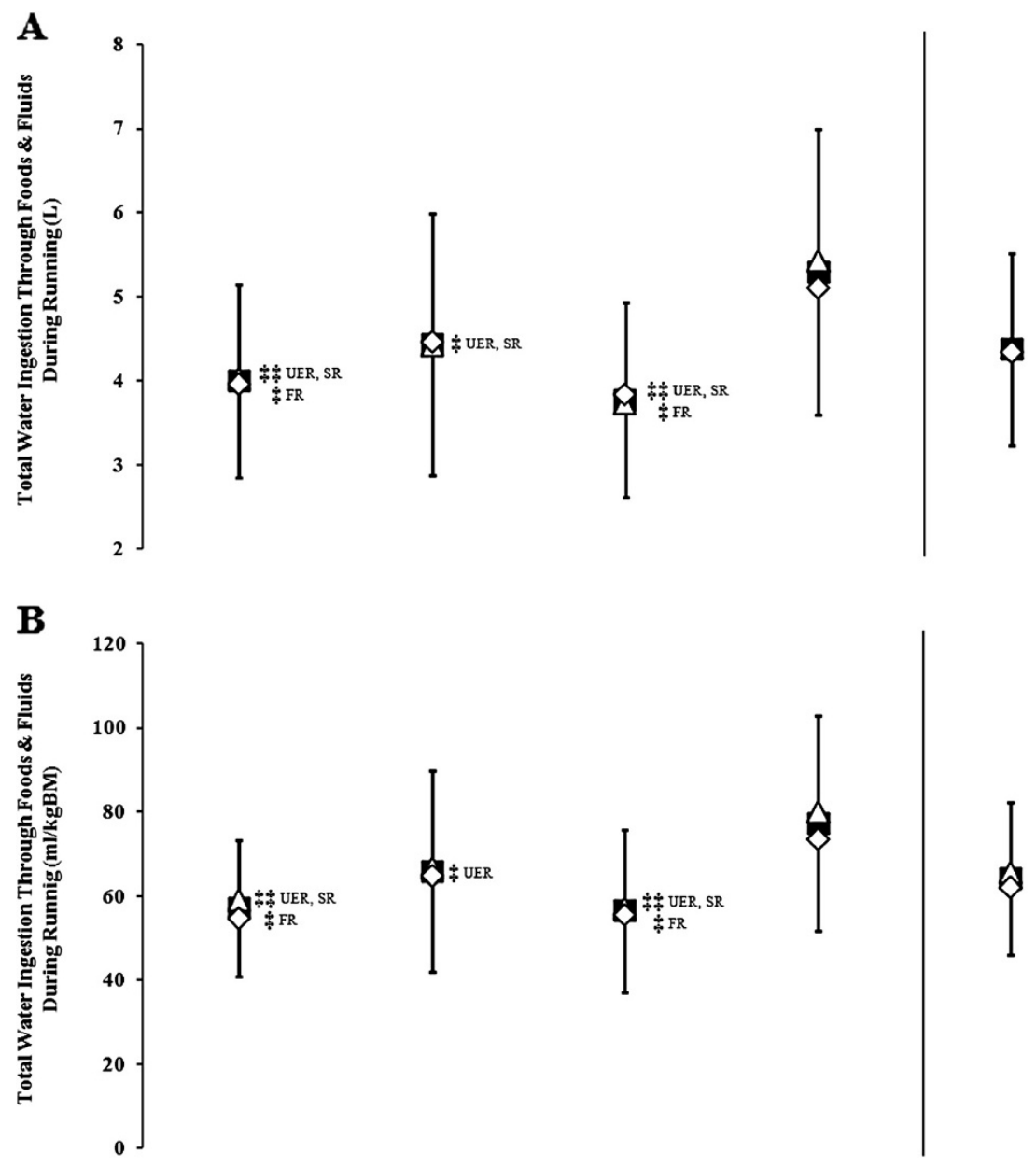

C
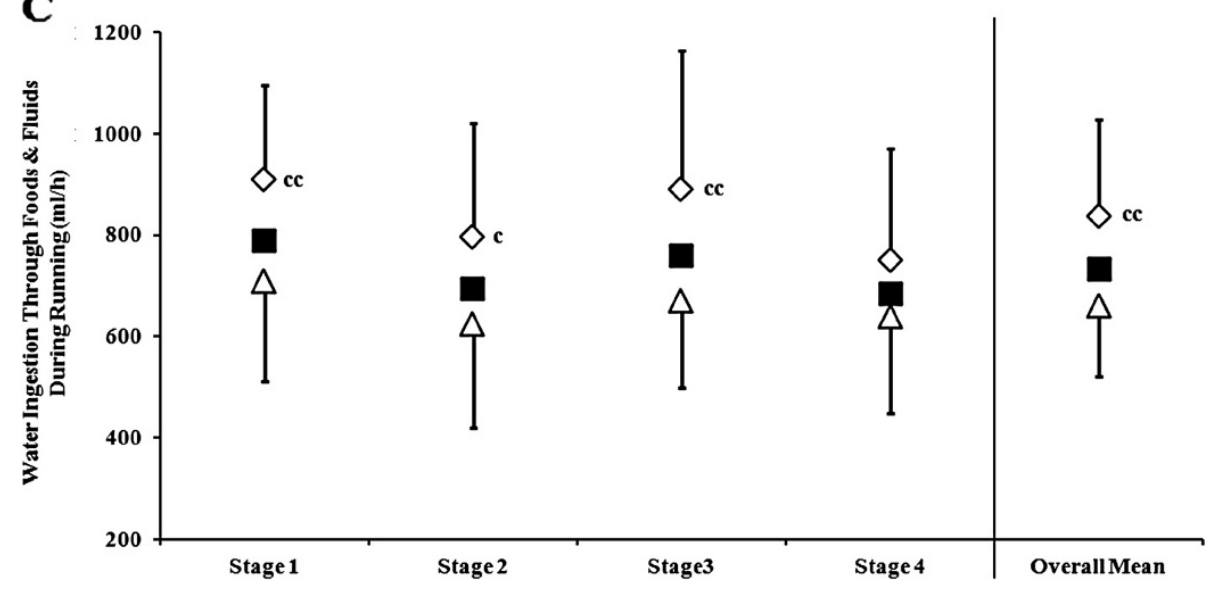

Figure 1 Water ingestion habits during running of UER along MSUM competition. (A) Total water ingestion, (B) Total water ingestion corrected for BM, (C) Rate of water ingestion. Mean (SD): UER ( $\mathbf{\square}, n=54)$, slow runners (SR $\triangle$; MSUM mean speed $<8 \mathrm{~km} / \mathrm{h}, n=32$ ), and fast runners (FR $\diamond$; MSUM mean speed $\geq 8 \mathrm{~km} / \mathrm{h}, n=22$ ). $\neq \neq p<0.01$ and $\neq p<0.05$ vs. Stage 4 ; ${ }^{c c} p<0.01$ and ${ }^{c} p<0.05$ vs. SR. 
day, female 7434 (1208) $\mathrm{ml} /$ day), pre-stage (male 899 (445) $\mathrm{ml}$, female $784(258) \mathrm{ml}$ ), during running (male 4429 (1313) $\mathrm{ml}$, female 4289 (834) $\mathrm{ml}$ ), and post-stage (male 1259 (569) ml, female 1145 (386) ml) water ingestion was observed between genders. When corrected for BM, female ultra-runners presented higher total daily (127 (20) $\mathrm{ml} / \mathrm{kgBM} /$ day; $p<0.001)$ and during running $(72(14) \mathrm{ml} /$ $\mathrm{kgBM} ; p<0.001)$ water ingestion on all stages compared with male ultra-runners $(106(27) \mathrm{ml} / \mathrm{kgBM} /$ day and 59 (19) $\mathrm{ml} / \mathrm{kgBM}$, respectively). However, rate of water ingestion during running was higher on all stage in male ultra-runners $(777(188) \mathrm{ml} / \mathrm{h} ; p<0.001)$ compared with female ultra-runners $(661(154) \mathrm{ml} / \mathrm{h})$.

\section{Dietary sodium intake}

Total daily sodium ingestion, through foods and fluids, did not vary between stages for UER (3.9 (1.3) g/day), SR (3.8 (1.3) g/day), and FR (4.2 (1.4) g/day) throughout the MSUM. Whereas, total daily sodium ingestion in $\mathrm{CON}$ was higher on Stage 4 ( $3.8 \mathrm{~g} /$ day) compared with Stages 1 to 3 (1.5 to $2.2 \mathrm{~g} /$ day; $p<0.000$ ). Total daily sodium ingestion was lower in CON on Stages 1 to 3 compared with UER $(p<0.001)$, and was lower in SR on Stages 3 and 4 compared with FR $(p=0.048)$. When total daily sodium ingestion is represented as sodium intake per litre of fluid volume ingested, no significant difference was observed between stages for UER (564 (268) mg/L), SR (584 (304) mg/ $\mathrm{L}$ ), and FR (534. (207) $\mathrm{mg} / \mathrm{L}$ ), nor between SR and FR within stages; which were under benchmark recommendations. However, CON showed a higher sodium intake per litre of fluid volume ingested on Stage $4(1133 \mathrm{mg} / \mathrm{L})$ compared with Stages 1 to 3 (519 to $682 \mathrm{mg} / \mathrm{L} ; p<0.000$ ), and compared with UER on Stage 4 only ( $549 \mathrm{mgNa} / \mathrm{L} ; p=0.007$ ).

Total sodium ingestion and sodium intake per litre of fluid volume ingested pre-stage did not vary between stages for UER (947 (538) mg; 1209 (614) mg/L), SR (1040 (584) mg; 1281 (617) mg/L), and FR (811 (443) mg; 1104 (607) $\mathrm{mg} / \mathrm{L}$ ); nor between SR and FR within stages. Total sodium ingestion and sodium intake per litre of fluid volume ingested during running did not vary between stages for UER (1096 (630) mg; 271 (155) mg/L), SR (1092 (588) mg; 269 (133) $\mathrm{mg} / \mathrm{L}$ ), and FR (1102 (702) mg; 275 (184) $\mathrm{mg} / \mathrm{L}$ ), nor between SR and FR within stages; which were under benchmark recommendations. Total sodium ingestion and sodium intake per litre of fluid volume ingested post-stage did not vary between stages for UER (456 (313) mg; 440 (372) mg/L), SR (475 (316) mg; 498 (428) mg/L), and FR (428 (314) mg; 356 (259) $\mathrm{mg} / \mathrm{L}$ ), nor between SR and FR within stages; which were under benchmark recommendations. Moreover, overall daily, pre-stage, during running, and post-stage total sodium ingestion and sodium intake per litre of fluid volume ingested did not differ between genders in all stages, and were under benchmark recommendations.

\section{Serum sodium concentration}

Pre-stage $\mathrm{S}_{\mathrm{Na}}$ concentration of sampled participants $(n=19)$ was lower on Stages 2 and 3, compared with Stage 1 , in UER ( $p=0.001$; Figure $2 \mathrm{~A})$ and SR $(p=0.025)$, but did not change in FR. While, post-stage $\mathrm{S}_{\mathrm{Na}}$ concentration of sampled participants did not differ in UER, SR, and FR between stages. Pre- and post-stage $\mathrm{S}_{\mathrm{Na}}$ concentration did not differ between SR and FR within stages. Significant increases in pre- to post-stage $\mathrm{S}_{\mathrm{Na}}$ concentration only occurred on Stages 2 and 5 in UER and SR $(p=0.001)$. $\mathrm{S}_{\mathrm{Na}}$ concentration indicative of normonatraemia were evident in sampled UER along the course of the MSUM, with no episodes of hypernatraemia observed. However, $S_{\mathrm{Na}}$ concentrations indicative of hyponatraemia $(<135 \mathrm{mmol} / \mathrm{L})$ [24] were evident in $n=8$ of UER (SR: $n=4$, FR: $n=4$ ) sampled along the MSUM (corresponding to $42 \%$ of the sampled population), occurring both pre- (Stages 1 to 4 ) and post-stage (Stages 2 to 4; Figure 2B). Moreover, preand post-stage $\mathrm{S}_{\mathrm{Na}}$ concentration did not differ between male and female ultra-runners within stages along the MSUM. $\mathrm{S}_{\mathrm{Na}}$ concentrations indicative of hyponatraemia was evident in both male and female ultra-runners (corresponding to $38 \%$ and $50 \%$ of sampled males and females, respectively) throughout the MSUM.

\section{Body mass}

Pre- and post-stage BM did not differ between stages in UER, CON (pre-stage only), SR, and FR throughout the MSUM. However, BM loss did occur from pre- to poststage in UER, SR, and FR in all stages (pre-stage: UER 69.5 (11.0) kg, SR 67.8 (11.7) kg, FR 71.6 (9.9) kg; post-stage: UER 67.8 (10.6) kg, SR 66.3 (11.4) kg, FR 69.7 (9.4) kg). Stage 1 induced a greater BM loss compared with Stages 2 to 5 in UER $(p<0.001)$ and SR $(p<0.001)$, and Stage 3 only in FR $(p=0.021$; Figures 3A). Additionally, FR showed a greater exercise-induced BM loss compared with SR in Stages 3 and $4(p<0.001)$. Pre- to post-stage BM gains along the course of the MSUM were evident in 29\% of SR (Figure 3B), and $21 \%$ of FR (Figure 3C). Moreover, exercise-induced $\mathrm{BM}$ loss was greater in male ultrarunners $(p<0.001)$ on Stages 1 to $3(3.4(1.7) \%, 2.8(1.4) \%$, and $1.9(1.4) \%$, respectively) compared with female ultrarunners (2.6 (1.7)\%, $1.5(1.6) \%$, and $1.0(1.5) \%$, respectively). Pre- to post-stage BM gains was evident in both genders (males 22\%, females 32\%).

\section{Plasma osmolality, plasma volume change, and body water}

Pre- and post-stage $\mathrm{P}_{\mathrm{Osmol}}$ did not differ between stages in UER, CON (pre-stage only), SR, and FR; and between UER and CON, nor SR and FR within stages throughout the MSUM (Table 4). $\mathrm{P}_{\text {Osmol }}$ increased pre- to post-stage in UER $(p<0.001)$, SR $(p<0.001)$, and FR $(p<0.001)$ on all stages. In UER, mean $\mathrm{P}_{\text {Osmol }}$ remained within normal clinical reference range (280-303 $\mathrm{mOsmol} / \mathrm{kg})$ [32] 

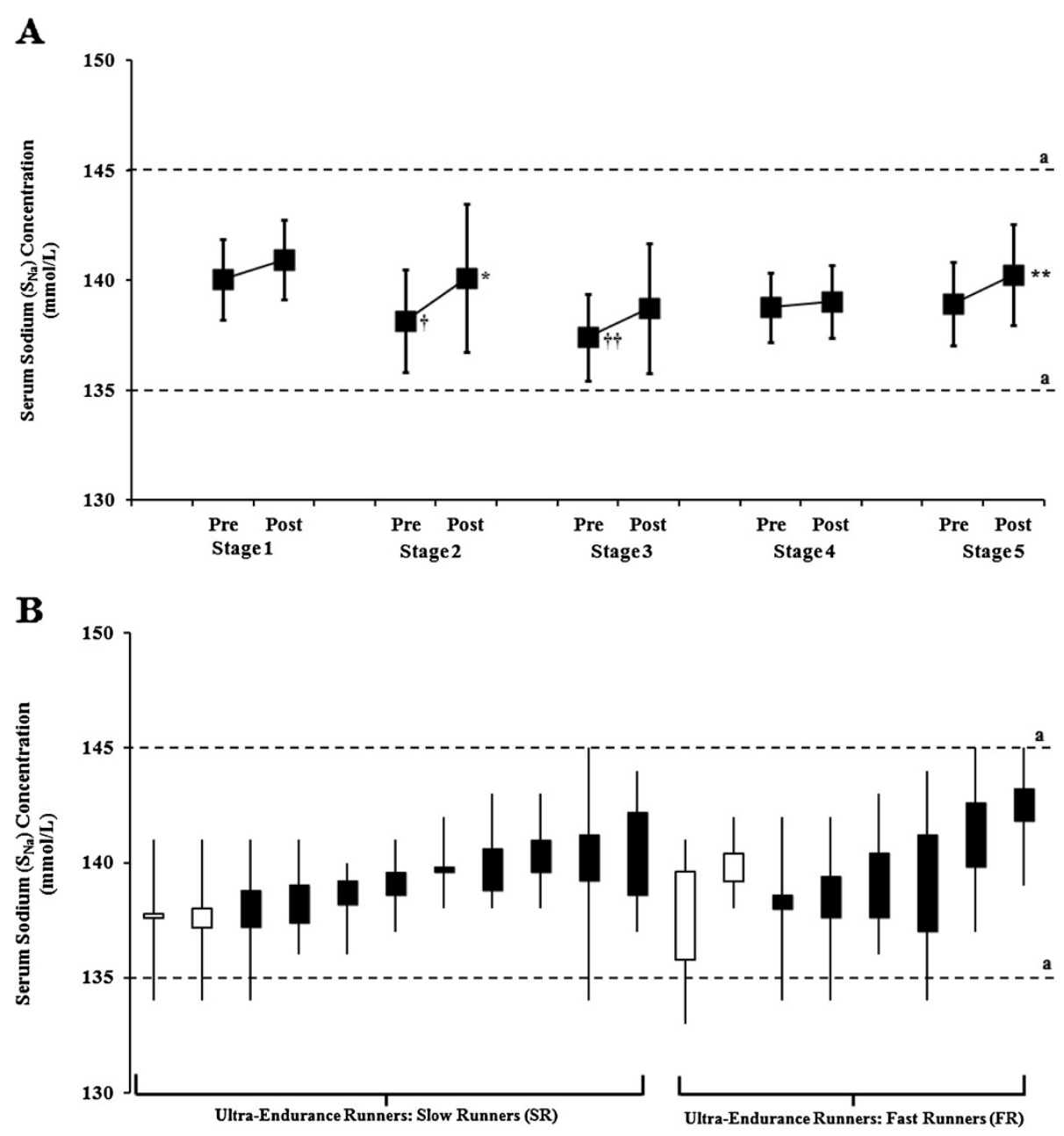

Figure 2 Serum sodium $\left(S_{\mathrm{Na}}\right)$ responses of UER along MSUM competition. (A) $\mathrm{S}_{\mathrm{Na}}$ concentration, (B) Individual $\mathrm{S}_{\mathrm{Na}}$ responses. Mean (SD): $\operatorname{UER}(\mathbf{\square}, n=19)$, slow runners (SR; MSUM mean speed $<8 \mathrm{~km} / \mathrm{h}, n=11$ ), and fast runners (FR; MSUM mean speed $\geq 8 \mathrm{~km} / \mathrm{h}, n=8)$. ${ }^{a}$ Normal physiological range 135 to $145 \mathrm{mmol} / \mathrm{L}$ [32]; hyponatraemia $<135 \mathrm{mmol} / \mathrm{L}$ [24]. Closed bars represent a pre- to post-stage increase in $\mathrm{S}_{\mathrm{Na}}$ concentration. Open bars present a pre- to post-stage decrease in $\mathrm{S}_{\mathrm{Na}}$ concentration. $+\dagger p<0.01$ and $+p<0.05$ vs. pre-Stage $1 ;{ }^{* *} p<0.01$ and ${ }^{*} p<0.05$ vs. pre-stage.

throughout the MSUM, except on pre-Stages 3 and 4 (under normal clinical reference range). $\mathrm{P}_{\text {Osmol }}$ was higher in male ultra-runners on pre-Stage 2 only (288 (14) $\mathrm{mOsmol} / \mathrm{kg} ; p=0.031$ ) compared with female ultrarunners (274 (18) $\mathrm{mOsmol} / \mathrm{kg})$. No significant difference in post-stage $\mathrm{P}_{\text {Osmol }}$ was observed between genders.

From baseline (pre-Stage 1), a significant increase in $\mathrm{P}_{\mathrm{V}}$ was evident pre-Stage 3 onwards in UER $(+9.7 \%)$, SR $(+8.0 \%)$, and FR $(+12.0 \% ; p<0.001)$; peaking at pre-Stage $5(+20.4 \%,+18.6 \%$, and $+22.8 \%$, respectively). No significant change in $\mathrm{P}_{\mathrm{V}}$ was observed in CON. UER presented a significantly higher $\mathrm{P}_{\mathrm{V}}$ than CON $(p=0.001)$ preStages $3(+6.2 \%)$ and $5(+18.6 \%)$. No difference in $\mathrm{P}_{\mathrm{V}}$ was observed between SR and FR, nor between genders, within stages throughout the MSUM.

Pre-stage total body water did not differ between stages in UER, SR, and FR (Figure 4A). SR presented a lower pre-stage total body water on Stages 1, 3 and 5 $(p<0.001)$ compared with FR. Pre-stage extra-cellular water was significantly higher on Stage 5 compared with Stage 1 in UER $(p=0.012)$ and SR $(p=0.05)$, but did not differ between stages in FR (Figure 4B). SR presented lower pre-stage extra-cellular water on Stages 1 and $2(p<0.001)$ compared with FR. Pre-stage intra-cellular water did not differ significantly between stages in UER, SR, and FR (Figure 4C). SR presented lower pre-stage intra-cellular water on Stages 1 and $4(p<0.001)$ compared with FR. Pre-stage total body, extra-cellular, and intra-cellular water was higher $(p<0.001)$ in male ultrarunners on all stage (46.8 (5.9) L, 19.1 (1.8) L, and 26.1 (2.8) L, respectively) compared with female ultra-runners (36.7 (5.2) L, 16.2 91.8) L, and 19.4 (3.4) L, respectively). However, when corrected for BM, no significant difference in pre-stage total body, extra-cellular, and intra-cellular 

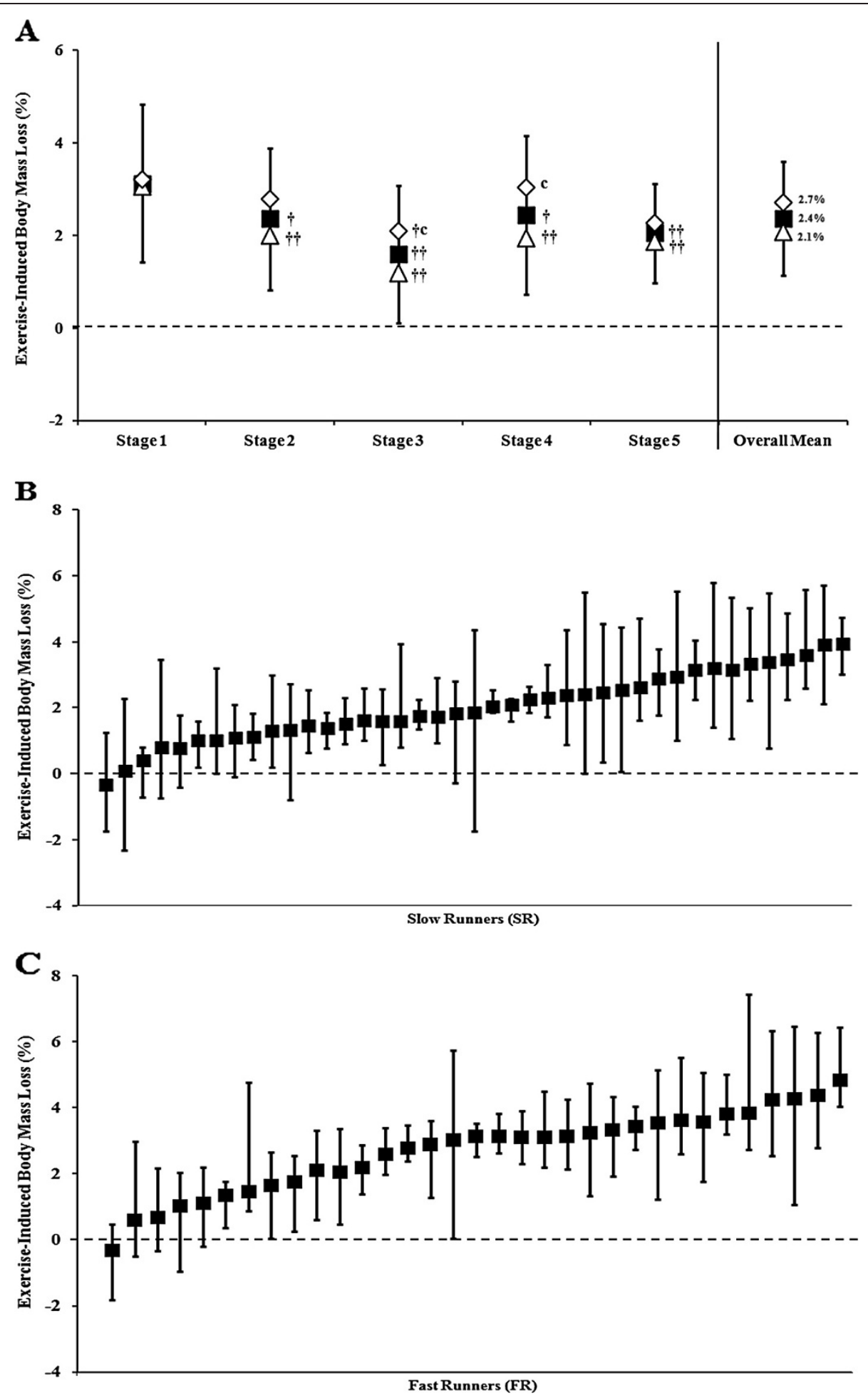

Figure 3 Exercise-induced BM loss of UER along MSUM competition. Mean (SD): (A) UER ( $\mathbf{\square}, n=74)$; (B) slow runners (SR $\triangle$; MSUM mean speed $<8 \mathrm{~km} / \mathrm{h}, n=41$ ); (C) fast runners (FR $\diamond ;$ MSUM mean speed $\geq 8 \mathrm{~km} / \mathrm{h}, n=33$ ). $+\dagger p<0.01$ and $+p<0.05$ vs. Stage 1 ; ${ }^{c} p<0.05$ vs. SR. 
Table 4 Plasma $\left(\mathrm{P}_{\text {Osmol }}\right)$ and urine $\left(\mathrm{U}_{\text {Osmol }}\right)$ osmolality, and $\mathrm{U}_{\text {Osmol }} / \mathrm{P}_{\text {Osmol }}$ ratio of UER along MSUM competition

\begin{tabular}{|c|c|c|c|c|c|c|c|c|c|c|}
\hline & \multicolumn{2}{|c|}{ Stage 1} & \multicolumn{2}{|c|}{ Stage 2} & \multicolumn{2}{|c|}{ Stage 3} & \multicolumn{2}{|c|}{ Stage 4} & \multicolumn{2}{|c|}{ Stage 5} \\
\hline & Pre & Post & Pre & Post & Pre & Post & Pre & Post & Pre & Post \\
\hline \multicolumn{11}{|c|}{ Plasma Osmolality (mOsmol/kg) } \\
\hline UER & $281(16)$ & $287(14)^{*}$ & $283(16)$ & $297(17)^{*}$ & $272(13)$ & $291(16)^{* *}$ & $271(12)$ & $298(10)^{* *}$ & $283(15)$ & $296(10)^{* *}$ \\
\hline CON & $287(13)$ & & & & $276(14)$ & & & & $270(9)$ & \\
\hline$S R$ & $280(18)$ & $286(17)^{*}$ & $282(17)$ & $294(16)^{*}$ & $273(15)$ & $287(16)^{* *}$ & $270(10)$ & $298(6)^{* *}$ & $286(13)$ & $294(10)^{*}$ \\
\hline $\mathrm{FR}$ & $282(12)$ & $289(9)^{*}$ & $285(11)$ & $302(18)^{* *}$ & $271(9)$ & $297(14)^{* *}$ & $273(14)$ & $299(14)^{* *}$ & $278(17)$ & $298(11)^{* *}$ \\
\hline \multicolumn{11}{|c|}{ Urine Osmolality (mOsmol/kg) } \\
\hline UER & $535(278)$ & $811(261)^{* *}$ & $673(311)$ & $914(367)^{* *}$ & $792(306)^{\dagger+b}$ & $997(352)^{* * t}$ & $750(293)^{\dagger+}$ & $898(333)^{* *}$ & $834(343)^{+\dagger}$ & $1050(402)^{* *+\dagger}$ \\
\hline CON & $577(197)$ & & & & $545(78)$ & & & & 608 (349) & \\
\hline SR & $514(295)$ & $840(226)^{* *}$ & $702(326)$ & $969(393)^{* *}$ & $849(294)^{\dagger+}$ & $1075(356)^{* *+\dagger}$ & $770(301)^{\dagger+}$ & $939(323)^{* *}$ & $846(355)^{\dagger+}$ & $1086(400)^{* *+\dagger}$ \\
\hline$F R$ & $562(256)$ & $775(298)^{* *}$ & $636(293)$ & $844(324)^{* *}$ & $722(311)$ & $899(326)^{* * c}$ & $724(285)$ & $847(344)^{* *}$ & $818(334)^{\dagger}$ & $1004(406)^{* *}$ \\
\hline \multicolumn{11}{|c|}{ Urine to Plasma Osmolality ratio } \\
\hline UER & $2.0(0.6)$ & $2.7(0.9)^{* *}$ & $2.6(1.0)$ & $3.3(1.1)^{* *}$ & $3.3(1.0)^{+t b b}$ & $3.9(1.2)^{++^{* *}}$ & $3.1(1.0)^{\dagger+}$ & $3.3(1.0)^{* *}$ & $3.5(1.1)^{t+b b}$ & $4.2(1.3)^{++* *}$ \\
\hline CON & $2.0(0.3)$ & & & & $2.0(1.0)$ & & & & $2.2(1.2)$ & \\
\hline$S R$ & $2.0(0.7)$ & $2.8(0.9)^{* *}$ & $2.8(1.0)$ & $3.7(1.3)^{* * c c}$ & $3.5(0.9)^{\dagger \dagger}$ & $4.2(1.1)^{\dagger+* *}$ & $3.2(1.0)^{+\dagger}$ & $3.3(1.0)^{* *}$ & $3.6(1.1)^{\dagger \dagger}$ & $4.4(1.2)^{\dagger+* *}$ \\
\hline$F R$ & $2.1(0.6)$ & $2.6(0.9)^{* *}$ & $2.1(1.0)$ & $2.8(1.3)^{* *}$ & $3.1(1.0)^{\dagger}$ & $3.5(1.1)^{* *}$ & $3.1(1.0)^{\dagger}$ & $3.3(0.9)^{* *}$ & $3.4(1.3)^{\dagger \dagger}$ & $4.0(1.5)^{+*^{* *}}$ \\
\hline \multicolumn{11}{|c|}{ Individual UER response range ( $\cup_{\text {Osmol }} / \mathrm{P}_{\text {Osmol }}$ ratio) } \\
\hline & 0.6 to 2.9 & 0.9 to 4.0 & 0.4 to 4.6 & 0.5 to 6.1 & 1.3 to 4.8 & 1.6 to 6.1 & 1.1 to 4.7 & 1.1 to 5.0 & 0.9 to 5.4 & 1.1 to 6.6 \\
\hline
\end{tabular}

water was observed between SR and FR, nor between male and female ultra-runners.

\section{Urine measures}

Pre-stage $\mathrm{U}_{\text {Colour }}$ was darker on Stages 2 to 5 in UER (4 to 6), SR ( 4 to 6), and FR ( 4 to 6) compared with Stage 1 (3 (1)); but did not significantly change in CON (3 (1)) along the MSUM. UER presented a darker $\mathrm{U}_{\text {Colour }}$ on pre-Stages 3 and 5 compared with CON $(p=0.004)$; whereas, no difference in pre-stage $U_{\text {Colour }}$ was observed between SR and FR within stages. No difference in post-stage $U_{\text {Colour }}$ was observed between stages in UER (6 (1)), SR (6 (1)), and FR (6 (1)); nor between SR and FR within stages. Increases darkness in $\mathrm{U}_{\text {Colour }}(p<0.001)$ were observed pre- to poststage on all stages for UER, SR, and FR. Moreover, no significant difference in pre- and post-stage $U_{\text {Colour }}$ was observed between male and female ultra-runners.

Pre-stage $\mathrm{U}_{\text {Osmol }}$ was higher on Stages 3 to 5 in UER (FR $(p<0.001)$ and SR $(p<0.001)$, and Stage 5 only in FR $(p=0.01)$, compared with Stage 1 ; but did not significantly change in CON (Table 4). UER presented a higher $\mathrm{U}_{\text {Osmol }}$ on pre-Stage 3 only compared with $\mathrm{CON}$ $(p=0.008)$. Post-stage $\mathrm{U}_{\text {Osmol }}$ was higher on Stages 3 and 5 in UER $(p<0.001)$ and SR $(p=0.009)$, compared with Stage 1; but did not differ between stages in FR. Increases in $\mathrm{U}_{\text {Osmol }}$ were observed pre- to post-stage on all stages for UER $(p<0.001)$, SR $(p<0.001)$, and FR $(p<0.001)$.
Moreover, a higher pre- $(p<0.001)$ and post-stage $(p=0.008)$ $\mathrm{U}_{\text {Osmol }}$ was observed on Stage 5 only in males ultrarunners (907 (326) mOsmol/kg, 1126 (392) mOsmol/kg, respectively) compared with female ultra-runners (697 (339) $\mathrm{mOsmol} / \mathrm{kg}, 905$ (387) mOsmol/kg, respectively).

Similarly, pre-stage $\mathrm{U}_{\text {Osmol }} / \mathrm{P}_{\text {Osmol }}$ ratio was higher on Stages 3 to 5 in UER $(p<0.001)$, SR $(p<0.001)$, and FR $(p=0.022)$, compared with Stage 1 ; but did not significantly change in CON (Table 4). UER presented a higher $\mathrm{U}_{\text {Osmol }} / \mathrm{P}_{\text {Osmol }}$ ratio on pre-Stages 3 and 5 compared with CON $(p<0.001)$; whereas did not differ between SR and FR within stages. Post-stage $\mathrm{U}_{\text {Osmol }} / \mathrm{P}_{\text {Osmol }}$ ratio was higher on Stages 3 and 5 in UER $(p<0.001)$ and SR $(p<0.001)$, and Stage 5 only in FR $(p=0.049)$, compared with Stage 1. A higher $\mathrm{U}_{\text {Osmol }} / \mathrm{P}_{\text {Osmol }}$ ratio was observed in $\mathrm{SR}$ compared with FR on post-Stage 2 only $(p=0.046)$. Increases in $\mathrm{U}_{\text {Osmol }} / \mathrm{P}_{\text {Osmol }}$ ratio were observed pre- to post-stage on all stages for UER $(p<0.001)$, SR $(p<0.001)$, and FR $(p=0.038)$. Moreover, pre-stage $\mathrm{U}_{\text {Osmol }} / \mathrm{P}_{\text {Osmol }}$ ratio was higher in male ultra-runners on Stages 3 to 5 (3.7 (0.8), $3.4(0.9)$, and $3.6(0.9)$, respectively; $p<0.001)$ compared with female ultra-runners (2.5 (1.0), 2.4 (0.8), and 2.5 (1.2), respectively). While, post-stage $\mathrm{U}_{\text {Osmol }} / \mathrm{P}_{\text {Osmol }}$ ratio was also higher in male ultra-runners on Stages 3 to 5 (4.3 (1.0), $3.6(0.9)$, and $4.6(1.1)$, respectively; $p<0.001)$ compared with female ultra-runners (3.0 (1.1), $2.6(0.8)$, and 3.1 (1.3), respectively). 

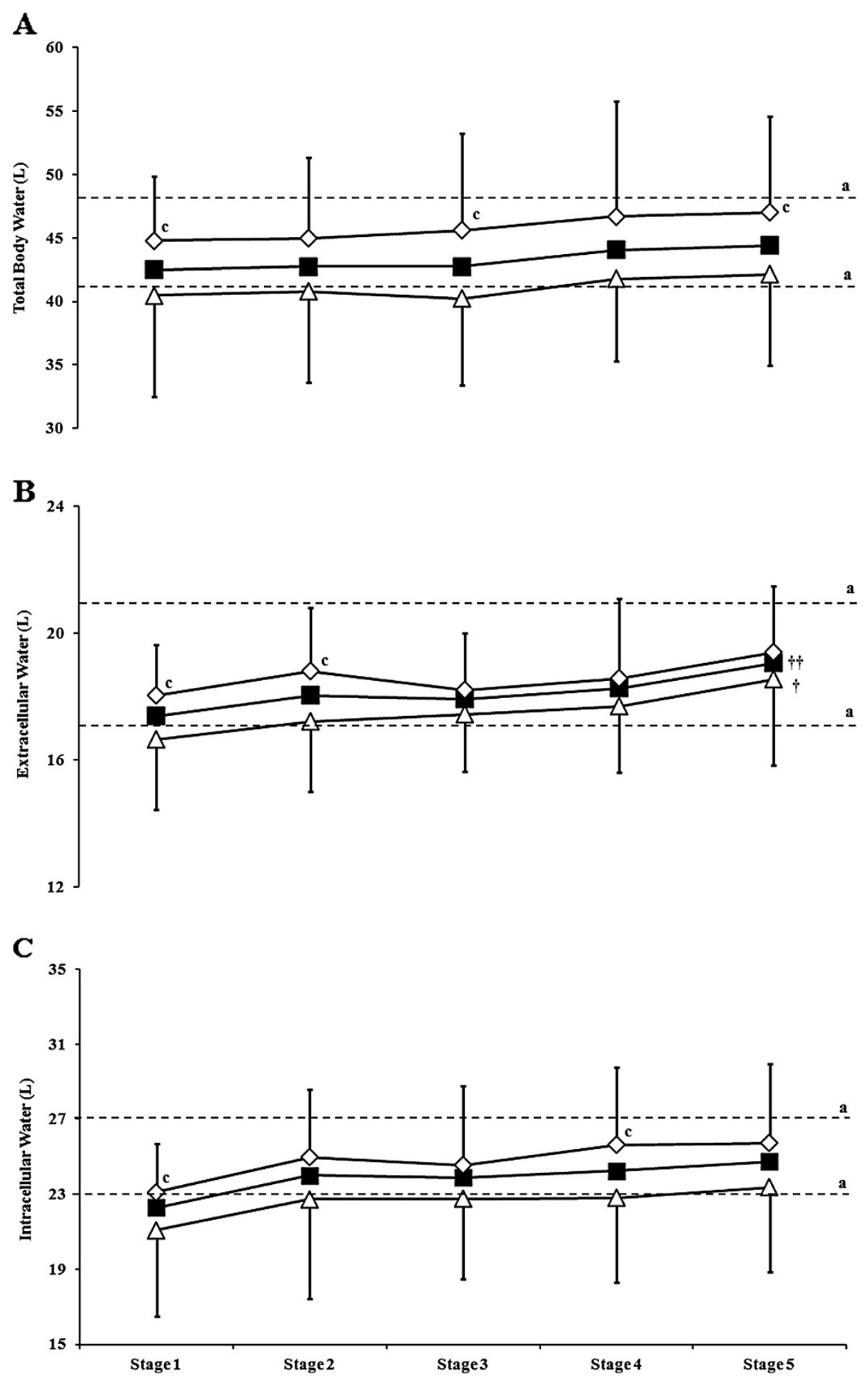

Figure 4 Changes in pre-stage resting body water of UER along MSUM competition. (A) Total body water, (B) Extra-cellular water, (C) Intra-cellular water. Mean (SD): UER ( $\mathbf{\square}, n=43$ ); slow runners (SR $\Delta ;$ MSUM mean speed $<8 \mathrm{~km} / \mathrm{h}, n=23$ ); fast runners (FR $\diamond$; MSUM mean speed $\geq 8 \mathrm{~km} / \mathrm{h}, n=20$ ). ${ }^{a}$ Normal physiological range (Quadscan 4000, Bodystat, Douglas, Isle of Man, UK). t十 $p<0.01$ and $+p<0.05 \mathrm{vs.} \mathrm{Stage} 1$; ${ }^{c}$ $p<0.05$ vs. SR. 


\section{Discussion}

The aims of the current study were, firstly to assess water and sodium intake habits of recreational ultrarunners during a semi self-sufficient MSUM conducted in a hot ambient environment; secondly to monitor serum sodium concentration, and hydration status using multiple hydration assessment techniques, along competition. In contrast to our hypothesis, water intake habits in the majority of UER were sufficient to maintain baseline euhydration levels whilst competing on consecutive days in hot ambient conditions. Despite sodium ingestion through foods and fluids under benchmark recommendations in the majority of UER, in accordance with our hypothesis, normonatraemia was observed in all UER along the MSUM. However, a novel finding was evidence of fluid over-consumption behaviours in a substantial number of UER, irrespective of running speed or gender, with asymptomatic hyponatraemia observed at certain points along the MSUM in $n=8$ UER (corresponding to $42 \%$ population). The strength of the sample size (equating to $55 \%$ of all runners that participated in the MSUM), potentially gives a valid and reliable representation of current water and sodium intake habits and status of ultra-runners during semi self-sufficient MSUM conducted in hot ambient conditions, bearing in mind the diverse origins of the sampled population. Conversely, the extreme nature of the event and invasive techniques used to determine blood borne variables at frequent points along the MSUM created a potential barrier for obtaining full data sets from all participants. In light of this, only a sub-sample of the full population was used in determining blood borne variables.

Average total daily water ingestion through foods and fluids of UER was $7.7 \mathrm{~L} /$ day, and appears to be sufficient to maintain baseline euhydration levels throughout the current semi self-sufficient MSUM, in accordance with the maintained $\mathrm{P}_{\text {Osmol }}$ within normal clinical reference range both pre- and post-stage in the majority of UER. This ad libitum rate of water ingestion also provided a surplus of water required to supported the acute extracellular hypervolaemia observed in both $\mathrm{SR}$ and FR along competition (as indicated by $22.8 \% \mathrm{P}_{\mathrm{V}}$ and $9.2 \%$ ECW increase in UER). This response is likely attributed to heat acclimatisation [5], since $72 \%$ of UER originated from countries that presented cold or thermoneutral environmental conditions $\left(\leq 20^{\circ} \mathrm{C}\right)$, and arrived at the competition location $<48 \mathrm{~h}$ prior the start of competition, without having previously heat acclimatised. These results also highlight practical relevance for selfsufficient MSUM, which normally provide water rations of $\sim 12 \mathrm{~L} /$ day; suggesting that even with a water quota set by race organisers, euhydration can easily be maintained throughout competition. However, the quality of fluids ingested by UER could be adjusted, since the majority of fluid consumed was plain water, with nutrient rich fluids only accounting for $\leq 30 \%$ of overall fluid intake along the course of the MSUM. Educating UER to predominantly consume nutrient rich fluids throughout competition will contribute towards both euhydration and cater for meeting energy and nutritional needs on consecutive days of strenuous exercise [39].

Average total water intake through foods and fluids during running in UER was $4.5 \mathrm{~L}$, with FR and male ultra-runners showing ability to tolerate higher rates of fluid consumption than SR and female ultra-runners, respectively. Thirst and appetite sensations, gastrointestinal distress during running, concomitant with training status and degree of exposure to competition beverages during training, are all are prime factors to fluid tolerance during exercise-heat stress $[8,11,40,41]$. The majority of fluid consumed during running was plain water, with nutrient rich fluids only accounting for $\leq 26 \%$ of overall fluid intake. Such drinking behaviours during running are prime risk factor for hyponatraemia $[17,24,26]$, with prevalence on hyponatraemia observed during a one stage $161 \mathrm{~km}$ running event [42]; and now during a 5 stage $225 \mathrm{~km}$ ultra-marathon in the heat, with $26 \%$ of UER sampled presenting exercise-associated hyponatraemia post-stage along the MSUM, irrespective of running speed, running distance, and/or gender; with incidence not accumulating over the MSUM. The interesting feature of the current study was that $\mathrm{S}_{\mathrm{Na}}$ indicative of hyponatraemia also occurred pre-stage $(16 \%$ of UER sampled). Therefore, over-consumption of plain water during the recovery period and/or sub-optimal dietary sodium intakes may have also attributed to the incidences of asymptomatic hyponatraemia observed $[6,18,19,26]$. Indeed, even though the majority of UER were actively adding external sodium supplementation to ingested fluids, sodium intake per ingested fluid volume during running and the recovery period were far below benchmark recommendation throughout the entire MSUM in UER $[6,18]$. Conversely, despite the low sodium concentrations per fluid volume ingested, 58\% of UER sampled remained normonatramic throughout the entire MSUM. These results are in accordance with previous studies suggesting that sodium supplementation may not be required during exercise in certain UER, since adaptations to increase sodium bioavailability and prevent losses (e.g. sweat, urine, and faeces) take place in response to periods of sodium deprivation or restriction $[14,23,24]$.

BM loss $\geq 2 \%$ has previously been established as indicative of dehydration [1]. In the current study the average exercise-induced BM loss in UER was $2.4 \%$, which is relatively low compared with reports of $>4 \%$ $\mathrm{BM}$ loss often observed after marathon and one-stage 
ultra-marathon competition [17]. Moreover, FR and male ultra-runners showed a greater exercise-induced BM loss compared with SR and female ultra-runners, respectively. This is in accordance with previous reports indicating highly trained faster runners lose more BM during competition than lesser trained slower runners [16,17]; but also present novel finding, showing that male ultra-runners lose more BM than female ultra-runner, possibly associated with running speed. Nevertheless, these results support the suggestion that $\mathrm{SR}$, and now female ultra-runners, have the increased tendency for fluid over-consumption; with BM gains observed pre- to post-stage in $29 \%$ and $32 \%$ of SR and female ultra-runners respectively, compared with $21 \%$ and $22 \%$ of FR and male ultra-runners respectively. BM loss results from a combination of factors during the run phase of MSUM competition in the heat, including: water sweat, respiratory, and urine losses (taking into account potential gastrointestinal fluid reservoirs, awaiting intestinal transport, during the pre-stage period), weight loss associated with depletion of muscle glycogen stores, and/ or faecal weight loss if evacuation is required during running $[2,6,29]$. Therefore, care is needed in using the degree of exercise-induced BM loss to programme fluid intake strategies during post-stage recovery, to correctly replace water sweat and obligatory urine losses. Water replacement rates after exercise of x1.5 BM loss have been recommended, and appear to be an effective and safe in replenishing exercise-heat stress induced body water losses [1]. Using nutrient rich fluids during the poststage recovery period (e.g. milk shake), will provide a plethora of essential ingredients required for an overall effective recovery [43-47].

The novel use of MBIA in the current field setting showed that euhydration was maintained throughout the entire course of the MSUM, with pre-stage hydration status actually improving along competition. The observed 9.2\% increase in resting pre-stage ECW from pre-Stage 1 to pre-Stage 5 in UER, are likely associated with heat acclimatisation responses promoting acute extracellular hypervolaemia [48-50]. Exercise-heat stress raises circulatory osmotic pressure stimulating a vascular influx of plasma proteins (e.g. albumin) which draws fluid into intravascular compartments, and up-regulates hormones (e.g. aldosterone, vasopressin) responsible for renal water re-absorption [5,51]. Even though $\mathrm{P}_{\mathrm{V}}$ expansion was not directly measured, using change in blood haemoglobin and haematocrit has previously been used as a valid method of estimating changes in $\mathrm{P}_{\mathrm{V}}$ during exercise-heat stress [16,35-37]. Increases in $\mathrm{P}_{\mathrm{V}}$ were observed in the current MSUM in UER, but not in CON, which are in accordance with ultraendurance specific heat acclimation protocols, reporting significant increases in $\mathrm{P}_{\mathrm{V}}(+7.9 \%)$ after two bouts of 2 hours running at $60 \% \mathrm{VO}_{2 \max }$ at $30^{\circ} \mathrm{C}$ [35]. These results imply that simply starting MSUM competition in the heat will support a positive effect on hydration status if sufficient fluids are consumed to accompany heat adaptation responses.

Using urine measure of hydration to guide fluid intake and support euhydration is a common practice amongst ultra-endurance athletes during multi-stage competitions. Whereby, ultra-endurance athletes consume fluids based on their urine concentration (e.g. colour, osmolality). In the current study, pre-stage $\mathrm{U}_{\mathrm{Osmol}}$ and $\mathrm{U}_{\text {colour }}$ rose substantially by Stage 2 and remained elevated throughout the MSUM in UER, with no change on CON; whilst the high $U_{\text {Osmol }}$ values post-stage are a common feature of exercise-heat stress [28]. However, the substantial increase in $\mathrm{U}_{\text {Osmol }} / \mathrm{P}_{\text {Osmol }}$ ratio above clinical reference values in the majority of UER, irrespective of running speed and gender, at both pre- and post-stage, concomitant with progressive increases in $\mathrm{P}_{\mathrm{V}}$ and ECW observed as competition progressed, indicates $\mathrm{U}_{\text {Osmol }}$ does not reflect body water content; suggesting urine measure of hydration are potentially inappropriate in monitoring hydration status and guiding fluid intake strategies in UER during MSUM in the heat. Moreover, all UER who presented asymptomatic hyponatraemia and $\mathrm{BM}$ gains post-stage had $\mathrm{U}_{\text {Osmol }} / \mathrm{P}_{\text {Osmol }}$ ratios above clinical reference values. Interestingly, male ultra-runners presented greater $\mathrm{U}_{\text {Osmol }} /$ $\mathrm{P}_{\text {Osmol }}$ ratios compared with female ultra-runners Stage 3 onwards, likely due to the greater fluid over-consumption behaviours of female ultra-runners. However, differences in renal hormone responses between genders to exercise-heat stress should not be overlooked, and warrants further investigation. Even though a limitation in the current study is the absences of data on renal hormone responses during MSUM conducted in a hot ambient environment, previous ultra-endurance studies have reported a four-fold increase in vasopressin during a $109 \mathrm{~km}$ cycle race in the heat [25]. Thus, from a practical standpoint, using results from urine measure of hydration techniques to guide hydration strategies during periods of exercise-heat stress could actually be dangerous for certain individuals, promoting fluid overconsumption (attempts to maintain clear urine) while renal water re-absorption is up-regulated [22]. Using thirst as a mechanism to regulate fluid intake behaviour both during running and recovery appears to be a reliable and safer method in promoting euhydration maintenance along MSUM competition in the heat [13-15].

\section{Conclusion}

Water intake habits of recreational ultra-runners appear sufficient to maintain baseline euhydration levels during consecutive days of prolonged strenuous exercise in hot ambient conditions. The observed high intakes of plain water, pre- to post-stage BM gains, evidence of asymptomatic hyponatraemia both pre- 
and post-stage, concomitant with the progressive increases in pre-stage body water as competition progressed suggests prevalence of fluid over-consumption behaviours in a substantial number of recreational ultrarunners, irrespective of running speed, running distance, and/or gender. Normonatraemia was observed along the MSUM in the majority of UER, despite sodium ingestion under benchmark recommendations. These findings suggest that relevant hydration education, which may include: adherence to a heat acclimation protocol in the week leading up to MSUM, 'drink to thirst', selection and ingestion of nutrient rich fluids during running and recovery, and increase the consumption of sodium rich foods during the recovery period, may contribute towards encouraging ultra-runners to establish more appropriate hydration optimising behaviours during future MSUM events. These improved behaviours should not only support euhydration and endurance running performance, but also mitigate the development of clinically significant episodes arising from both dehydration and over-hydration.

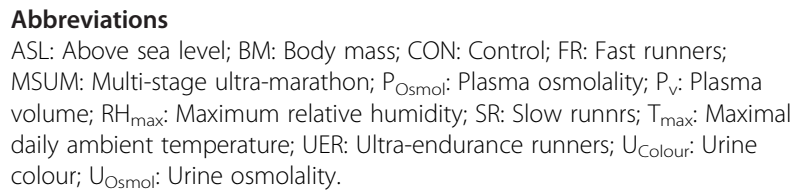

\section{Competing interests}

The authors declare that they have no competing interests.

\section{Authors' contributions}

$R C$ was responsible for the original research idea, overall supervision and management of the research project. RC, AT, LR, VS, AM, and CT contributed towards the development of the experimental design. RC, AT, LR, AS, LH, BL, $V C, S G, J W, E F, E D, J H, S M, E V, V S$, and AM contributed towards various aspects of data collection and sample analysis. RC and SG contributed towards analysis of the raw data. RC and CT contribute towards the preparation and review of the manuscript. All authors read and approved the final manuscript.

\section{Acknowledgments \\ Firstly, the authors would like to thank all the ultra-endurance runners that volunteered to participate in this study. The authors acknowledge the Al Andalus Ultimate Trail (www.alandalus-ut.com) race directors Paul Bateson and Barbara Price; and Team Axarsport SL: Michelle Cutler and Eric Maroldo, for assisting and supporting various aspects of this study. The authors also acknowledge Jane Sheehy and Jagdeep Shergill from Coventry University for their technical support along the course of the study implementation; Fátima Rosado, Grasiely Borges, Jose Rodrigues from the Faculty of Sport Science \& Physical Education, Coimbra University, Portugal for their technical support in sample analysis; Nina Godson, Sue Cresswell and Tim Morse for phlembotomy during the research design implementation. The study was partly funded by Coventry University as part of Dr. Ricardo Costa's Applied Research Fellowship, Coventry University Sport \& Exercise Science Applied Research Group, and the European Hydration Institute as part of Samantha Gill's Ph.D. programme.}

\section{Author details}

${ }^{1}$ Department of Health Professions, Coventry University, Priory Street, Coventry CV1 5FB, United Kingdom. ${ }^{2}$ Sport \& Exercise Science Applied Research Group, Coventry University, Priory Street, Coventry CV1 5FB, United Kingdom. ${ }^{3}$ Faculty of Sport Science \& Physical Education, Coimbra University, Pavilion 3, Santa Clara 3040-156, Portugal. ${ }^{4}$ School of Psychology, Bangor
University, Penralt Road, Bangor LL57 2AS, United Kingdom. ${ }^{5}$ Emergency Department, Vinalopo Salud Hospital, Calle Tonico Sansano Mora 14, Elche 03293, Spain. ${ }^{6}$ Sports Medicine Department, University of Heidelberg, Im Neunheimer Feld 710, Heidelberg 69120, Germany. ${ }^{7}$ SportsScotland Institute of Sport, Airthrey Road, Stirling FK9 5PH, United Kingdom.

Received: 8 September 2012 Accepted: 11 January 2013

Published: 15 January 2013

\section{References}

1. American College of Sports Medicine, Sawka MN, Burke LM, Eichner ER, Maughan RJ, Montain SJ, Stachenfeld NS: American college of sports medicine position stand. Exercise and fluid replacement. Med Sci Sports Exerc 2007, 39:377-390.

2. Maughan RJ, Shirreffs SM: Development of individual hydration strategies for athletes. Int I Sport Nutr Exerc Metab 2008, 18:457-472.

3. American College of Sports Medicine, Armstrong LE, Casa DJ, MillardStafford M, Moran DS, Pyne SW, Roberts WO: American college of sports medicine position stand. Exertional heat illness during training and competition. Med Sci Sports Exerc 2007, 39:556-572.

4. Noakes TD: A modern classification of the exercise-related heat illnesses. J Sci Med Sport 2008, 11:33-39.

5. Wendt $\mathrm{D}$, van Loon $\mathrm{L}$, Lichtenbelt WD: Thermoregulation during exercise in the heat: strategies for maintaining health and performance. Sports Med 2007, 37:669-682.

6. Heaney S, O'Connor H, Michael S, Gifford J, Naughton G: Nutrition knowledge in athletes: a systematic review. Int I Sport Nutr Exerc Metab 2011, 21:248-261.

7. Rehrer NJ: Fluid and electrolyte balance in ultra-endurance sport. Sports Med 2001, 31:701-715.

8. Rehrer NJ, Brouns F, Beckers EJ, Frey WO, Villiger B, Riddoch CJ, Menheere PP, Saris WH: Physiological changes and gastro-intestinal symptoms as a result of ultra-endurance running. Eur J Appl Physiol Occup Physiol 1992, 64:1-8.

9. Rehrer NJ, Meijer GA: Biomechanical vibration of the abdominal region during running and bicycling. J Sports Med Phys Fitness 1991, 31:231-234.

10. Ter Steege RWF, Geelkerken RH, Huisman AR, Kolkman JJ: Abdominal symptom during physical exercise and the role of gastrointestinal ischemia: a study in 12 symptomatic athletes. Br J Sport Med 2011, Epub(Oct).

11. van Wijck K, Lenaerts K, Grootjans J, Wijnands K, Poeze M, van Loon L, Dejong $\mathrm{CH}$, Buurman WA: Physiology and pathophysiology of splanchnic hypoperfusion and intestinal injury during exercise: strategies for evaluation and preventions. Am J Physiol 2012, Epub (April).

12. Winger JM, Dugas JP, Dugas LR: Beliefs about hydration and physiology drive drinking behaviours in runners. Br J Sports Med 2011, 45:646-649.

13. Goulet EDB: Effect of exercise-induced dehydration on endurance performance: evaluating the impact of exercise protocols on outcomes using a meta-analytic procedure. Br J Sports Med 2012, Epub (July).

14. Hew-Butler T, Verbalis JG, Noakes TD, International Marathon Medical Directors Association: Updated fluid recommendation: position statement from the international marathon medical directors association (IMMDA). Clin J Sport Med 2006, 16:283-292.

15. Noakes TD: Hydration in the marathon: using thirst to gauge safe fluid replacement. Sports Med 2007, 37:463-466.

16. Zouhal H, Groussard C, Minter G, Vincent S, Cretual A, Gratas-Delamarche A, Delamarche P, Noakes TD: Inverse relationship between percentage body weight change and finishing time in 643 forty-two-kilometre marathon runners. Br J Sports Med 2011, 45:1101-1105.

17. Noakes TD: Drinking guidelines for exercise: what evidence is there that athletes should drink "as much as tolerable", "to replace the weight lost during exercise" or "ad libitum"? J Sports Sci 2007, 25:781-796.

18. Maughan RJ: Fluid and electrolyte loss and replacement in exercise. J Sports Sci 1991, 9:117-142.

19. Shirreffs SM, Casa DJ, Carter R, International Association of Athletics Federations: Fluid needs for training and competition in athletics. $J$ Sports Sci 2007, 25:S83-S91.

20. Speedy DB, Noakes TD, Rogers IR, Thompson JM, Campbell RG, Kuttner JA, Boswell DR, Wright S, Hamlin M: Hyponatremia in ultradistance triathletes. Med Sci Sports Exerc 1999, 31:809-815. 
21. Vrijens DM, Rehrer NJ: Sodium-free fluid ingestion decreases plasma sodium during exercise in the heat. J App/ Physiol 1999, 86:1847-1851.

22. Hew-Butler T, Noakes TD, Siegel AJ: Practical management of exercise-associated hyponatremic encephalopathy: the sodium paradox of Non-osmotic vasopressin secretion. Clin J Sport Med 2008, 18:350-354.

23. Speedy DB, Thompson JM, Rodgers I, Collins M, Sharwood K, Noakes TD: Oral salt supplementation during ultradistance exercise. Clin J Sport Med 2002, 12:279-284.

24. Hew-Butler T, Ayus JC, Kipps C, Maughan RJ, Mettler S, Meeuwisse WH, Page AJ, Reid SA, Rehrer NJ, Roberts WO, Rogers IR, Rosner MH, Siegel AJ, Speedy DB, Stuempfle KJ, Verbalis JG, Weschler LB, Wharam P: Statement of the second international exercise-associated hyponatremia consensus development conference, New Zealand, 2007. Clin J Sport Med 2008, 18:111-121.

25. Hew-Butler T, Dugus JP, Noakes TD, Verbalis JG: Changes in plasma arginine vasopressin concentrations in cyclists participating in a 109-km cycle race. Br J Sports Med 2010, 44:594-597.

26. Noakes TD, Sharwood K, Speedy D, Hew T, Reid S, Dugas J, Almond C, Wharam $P$, Weschler $L$ : Three independent biological mechanisms cause exercise-associated hyponatremia: evidence from 2,135 weighed competitive athletic performances. Proc Natl Acad Sci USA 2005, 102:18550-18555.

27. Knechtle B, Knechtle P, Rust CA, Gnadinger M, Imoberdorf R, Kohler G, Rosemann T, Ballmer P: Regulation of electrolyte and fluid metabolism in multi-stage ultra-marathoners. Horm Metab Res 2012, Epub (May).

28. Armstrong LE: Assessing hydration status: the elusive gold standard. J Am Coll Nutr 2007, 26:575S-584S.

29. Maughan RJ, Shirreffs SM, Leiper JB: Errors in the estimation of hydration status from changes in body mass. J Sports Sci 2007, 25:797-804.

30. Armstrong LE, Maresh CM, Castellani JW, Bergeron MF, Kenefick RW, LaGasse KE, Riebe D: Urinary indices of hydration status. Int J Sport Nutr 1994, 1994(4):265-279.

31. Seifarth CC, Miertschischk J, Hahn EG, Hensen J: Measurement of serum and plasma osmolality in healthy young humans- influence of time and storage conditions. Clin Chem Lab Med 2004, 42:927-932.

32. Fischback FT, Dunning MB: A manual of laboratory and diagnostic tests $7^{\text {th }}$ edition. Philadelphia, PA: Lippincott Williams and Wilkins; 2004:964-969.

33. Dill DB, Costill DL: Calculation of percentage changes in volumes of blood, plasma, and red cells in dehydration. J Appl Physiol 1974, 37:247-248.

34. Maughan RJ, Leipers JB, Greaves M: Haematology. In Kinanthropometry and Exercise Physiology Laboratory Manual: Tests, Procedures and Data, Volume Two: Exercise Physiology. Edited by Eston RG, Reilly T. Oxon: Routledge; 2001:99-116.

35. Costa RJS, Crockford MJ, Moore JP, Walsh NP: Heat acclimation responses of an ultra-endurance running group preparing for hot desert based competition. Euro J Sport Sci 2012, Epub (March).

36. Garrett AT, Rehrer NJ, Patterson MJ: Induction and decay of short-term heat acclimation in moderately and highly trained athletes. Sports Med 2011, 41:757-771.

37. Nielsen B, Hales JR, Strange S, Christensen NJ, Warberg J, Saltin B: Human circulatory and thermoregulatory adaptations with heat acclimation and exercise in a hot, dry environment. J Physiol 1993, 460:467-485.

38. Cox GR, Snow RJ, Burke LM: Race-day carbohydrate intake of elite triathletes contesting olympic-distance triathlon events. Int J Sport Nutri Exerc Metab 2010, 20:299-306.

39. American College of Sports Medicine, American Dietetic Association, Dietitians of Canada: American college of sports medicine position stand. Nutrition and athletic performance. Med Sci Sports Exerc 2009, 41:709-731.

40. Rehrer NJ, Beckers EJ, Brouns F, ten Hoor F, Saris WH: Effects of dehydration on gastric emptying and gastrointestinal distress while running. Med Sci Sports Exerc 1990, 22:790-795.

41. Otte JA, Oostveen E, Geelkerken RH, Groeneveld AB, Kolkman JJ: Exercise induces gastric ischemia in healthy volunteers: a tonometry study. J Appl Physiol 2001, 91:866-871.

42. Lebus DK, Casazza GA, Hoffman MD, Van Loan MD: Can changes in body mass and total body water accurately predict hyponatremia after a 161-km running race? Clin J Sport Med 2010, 20:193-199.

43. Roy BD: Milk: the new sports drink? A Review. J Int Soc Sports Nutr 2008, 5:15-20.
44. Shirreffs SM, Watson P, Maughan RJ: Milk as an effective post-exercise rehydration drink. Br J Nutr 2007, 98:173-180.

45. Beelen M, Burke LM, Gibala MJ, van Loon LJC: Nutritional strategies to promote postexercise recovery. Int J Sport Nutri Exerc Metab 2010, 20:515-532.

46. Costa RJ, Oliver SJ, Laing SJ, Waiters R, Bilzon JL, Walsh NP: Influence of timing of postexercise carbohydrate-protein ingestion on selected immune indices. Int J Sport Nutri Exerc Metab 2009, 19:366-384.

47. Costa RJS, Walters R, Bilzon JLJ, Walsh NP: Effects of immediate postexercise carbohydrate ingestion with and without protein on neutrophil degranulation. Int J Sport Nutri Exerc Metab 2011, 21:205-213.

48. Fellmann N: Hormonal and plasma volume alterations following endurance exercise. A brief review. Sports Med 1992, 13:37-49.

49. Harrison MH: Effects on thermal stress and exercise on blood volume in humans. Physiol Rev 1985, 65:149-209.

50. Senay LC, Mitchell D, Wyndham CH: Acclimatization in a hot, humid environment: body fluid adjustments. J Appl Physiol 1976, 40:786-796.

51. Patterson MJ, Stocks JM, Taylor NA: Sustained and generalized extracellular fluid expansion following heat acclimation. J Physio/ 2004, 559:327-334.

doi:10.1186/1475-2891-12-13

Cite this article as: Costa et al:: Water and sodium intake habits and status of ultra-endurance runners during a multi-stage ultra-marathon conducted in a hot ambient environment: an observational field based study. Nutrition Journal 2013 12:13.

\section{Submit your next manuscript to BioMed Central and take full advantage of:}

- Convenient online submission

- Thorough peer review

- No space constraints or color figure charges

- Immediate publication on acceptance

- Inclusion in PubMed, CAS, Scopus and Google Scholar

- Research which is freely available for redistribution 